\title{
El desarrollo sostenible como nuevo saber ambiental
}

\section{The sustainable development like new environmental}

\author{
Alcides Antúnez Sánchez \\ Universidad de Granma, Facultad de Ciencias Económicas y Sociales, República de Cuba \\ aantunez@udg.co.cu
}

Fecha de recepción: 29/06/2018 Fecha de aceptación: 22/08/2018 Publicado: $26 / 12 / 2018$

\begin{abstract}
Resumen
En el ensayo se hace un análisis al principio del desarrollo sostenible como nuevo saber ambiental, por la necesidad de la formación jurídica ambiental como política de la Administración Pública en especial de las universidades, a partir de que el hombre en su relación con la naturaleza y a fin de lograr la conservación de las condiciones ambientales que requiere para su hábitat, sin perjuicio del desarrollo de las actividades económicas que lo impactan, necesita conocer como establecer los mecanismos, medidas y procedimientos que permitan una convivencia armónica de lo natural, de lo social y de lo económico. Los asuntos ambientales han ganado protagonismo en las discusiones en la sociedad internacional, incluyendo las conferencias de Estados, los foros académicos y los medios de comunicación. Se habla del calentamiento global; no obstante, los científicos corrigen y enfatizan en usar el término adecuado: "cambio climático". Se propone como objetivo, demostrar la necesidad de la formación jurídica ambiental en las universidades, que permita alcanzar el desarrollo sostenible dentro de las políticas públicas de los Estados como nuevo saber ambiental. Son utilizados los métodos de análisis síntesis, inducción deducción, y comparación jurídica.
\end{abstract}

Palabras clave: cambio climático, desarrollo sostenible, saber ambiental, formación ambiental 


\begin{abstract}
An analysis at the beginning of the sustainable development like new environmental knowledge, for the need plucks up the juridical environmental formation like policy of the Public Administration in special of the Universities in the essay, as from that the man in his relation with nature and in order to achieve the conservation of the environmental conditions that calls for for his habitat, without prejudice to development the economic activities that have impact on it, needs to know like establishing mechanisms, measures and procedures that they enable a harmonious cohabitation of a natural, of it social and of what's economic. The environmental subjects have earned prominence in the arguments in the international company, including States' lectures, the academic forums and the media. You are spoken to of global warming; Nevertheless, the scientists correct and emphasize in using the adequate term: "Climatic change". You set for yourself as objective, demonstrating the need of the juridical environmental formation at the Universities, that it allow attaining the sustainable development within the States' as good as new public policies to taste environmental. The methods of analysis are utilized synthesis, induction deduction, and juridical comparison.
\end{abstract}

Key words: Climatic change, sustainable development, tasting environmental, environmental formation

\title{
Glosa introductoria
}

El medio ambiente, ha sido asumido a lo largo de la evolución del "pensamiento filosófico y gnoseológico" del hombre como ser social, de diferentes maneras y diversas acepciones. El hombre en su relación con la naturaleza y a fin de lograr la conservación de las condiciones ambientales que requiere para su hábitat sin perjuicio del desarrollo de las actividades económicas que lo impactan, necesita establecer los mecanismos, medidas y procedimientos que permitan una convivencia armónica de lo natural, lo social y lo económico. El desarrollo tecnológico y las nuevas tecnologías no pueden ser depredadoras del medio ambiente. 
La implementación de los avances en las diferentes esferas de las ciencias, permiten encontrar soluciones para los nuevos desafíos económicos, sociales y ambientales, para con ello favorecer el desarrollo sostenible y las sociedades verdes en el siglo XXI. De hecho, como ningún país es capaz de alcanzar el desarrollo sostenible por sí solo, donde la cooperación científica internacional contribuye no sólo al progreso del conocimiento, sino también a la construcción de la paz.

Es una necesidad alcanzar el desarrollo sostenible en el siglo XXI, desde el Informe "Nuestro Futuro Común" en 1984, se señala como el mega principio del Derecho Ambiental, el paradigma es cómo establecer políticas públicas para concretarlo en cada nación. La educación ambiental como obligación pública, obedece a esta misma lógica de hacer efectiva una responsable participación de la ciudadanía en las decisiones de naturaleza ambiental, pero para participar es necesario estar informado como estar formado, de aquí que la formación jurídica ambiental por las Universidades se convierta en un paradigma, se necesita con ello dentro de las políticas públicas formar una conciencia ambiental, para ganar en cultura ambiental que tribute a la protección medio ambiental.

\section{El desarrollo sostenible, paradigma del siglo XXI en la protección ambiental. Necesidad de la formación jurídica ambiental}

En la actualidad se aprecia como los asuntos ambientales han ganado protagonismo en las discusiones que tienen lugar en la sociedad internacional, incluyendo en las conferencias de Estados, los foros académicos y en los medios de comunicación social. Se habla del calentamiento global; no obstante, los científicos corrigen y enfatizan en usar el término adecuado: “cambio climático".

Por ello, el medio ambiente en el siglo XXI se encuentra en el centro de atención de la comunidad internacional. Desde el Pacto Internacional de Derechos Civiles y Políticos (1966), y el Pacto Internacional de Derechos Económicos, Sociales y Culturales (1966), proclaman en su artículo 1: ...el derecho de los pueblos a la libre determinación, y en virtud "establecen libremente su condición política y proveen asimismo a su desarrollo económico social y cultural". Para el desarrollo de sus 
fines (artículo 1.2) ... "todos los pueblos pueden disponer libremente de sus riquezas y recursos naturales, sin perjuicio de las obligaciones que derivan de la cooperación económica internacional"

Pero no es a partir de la Asamblea General de Naciones Unidas, al convocar la Conferencia sobre el Medio Humano -Declaración de Estocolmo- en 1972, se reconoce como el hecho jurídico que marca un hito en el desarrollo del Derecho Ambiental y es a la vez su cita fundacional; es también el punto de conexión entre el Derecho Ambiental y el Derecho Internacional. Es este su punto de conexión en el Derecho Internacional Ambiental. Por la profundidad de sus conceptos, se le reconoce como la "Carta Magna" del Derecho Internacional Ambiental. (Juste, 2007). Aunque, en este sentido, Jordano (1995) considera desde su posición que ... "resulta artificioso y atrevido fijar una fecha concreta o una norma a partir de la cual se pueda se pueda situar el nacimiento del Derecho Ambiental moderno" ...

La Declaración de Estocolmo, se considera que posee el carácter de instrumento "soft law", con una tendencia antropocéntrica, define el medio ambiente como todo aquello que rodea al hombre: "el hombre es a la vez obra y artífice del medio que lo rodea". Dentro del grado de abstracción en que se considera el término, se usan expresiones como "el medio terráqueo del que dependen nuestra vida y nuestro bienestar", enunciando elementos como "el agua, el aire, la tierra y los seres vivos, [...] la biosfera, [...] los recursos insustituibles" así como "el medio por él creado [el hombre], especialmente aquel en que vive y trabaja".

Lo acontecido en Estocolmo, no cabe dudas que se realizó una reflexión sobre los problemas ambientales y sus causas que lo agreden. Se recomendó, que la educación centrara sus recursos en esta situación, mediante programas de educación ambiental. Aquí se aprecia cómo se comienza a visualizar la problemática ambiental como resultado de los procesos de desarrollo, y comienzan a buscarse conceptos alternativos de desarrollo, surgiendo la idea de ecodesarrollo propuesta por MAURICE STRONG, promovida entre los años 1980 y 1982. 
En este conclave internacional, se ponderó la importancia del establecimiento de un programa sobre educación ambiental para la sociedad mundial, con la finalidad de contribuir a la protección de la naturaleza (Valdés, 2002). Este hecho jurídico desde la arena internacional, se considera que constituyó el marco propicio para la creación de otros cuerpos jurídicos para favorecer la formulación de políticas en la materia ambiental. Se declara con ello, la necesidad de desarrollar una educación ambiental dirigida a la población adulta, hecho que constituyó las bases para el desarrollo de la educación ambiental no formal.

En este año 1972, se incluye en la lucha por defender el medio ambiente, a la cultura como parte constitutiva, al ser aprobada la Convención para la protección del patrimonio mundial cultural y natural, aunque influyó poco en la educación ambiental, se visualiza la necesidad de sistematizar las legislaciones dirigidas a la protección ambiental y al patrimonio cultural, y se delimita la necesidad de atender la relación sociedad-cultura-naturaleza.

En 1973, se crea el PNUMA, como el instrumento coordinador entre los organismos nacionales e internacionales, proporcionó gran impulso a la educación ambiental, lo que posibilitó que, en 1974, se desarrollara el seminario sobre educación ambiental organizado por la Comisión Nacional Finlandesa en Janini, donde se plantea que la educación ambiental se debe llevar a cabo de acuerdo con el principio de la educación integral permanente de la personalidad en el sistema educacional.

Para el año 1975, se crea el Programa Internacional de Educación Ambiental (PIEA) adscripto al PNUMA. Aquí se aprueba el primer proyecto trienal para definir los objetivos de la educación ambiental, investigar e intercambiar información, promover la elaboración y evaluación de materiales, planes de estudio, formación de personal y proporcionar asistencia técnica a los Estados miembros. Del mismo modo en 1975, se desarrolla el Seminario Internacional de educación ambiental en Belgrado, Yugoslavia, considerada la plataforma del lanzamiento oficial del PIEA. Se adoptó la "Carta de Belgrado", donde se fijan las metas y objetivos para la educación ambiental, se 
inicia la delimitación de su lugar y contenido, se formulan los principios de orientación de los programas de educación ambiental para todos los niveles de enseñanza carentes de una orientación interdisciplinar para su instrumentación desde el contenido académico.

En 1976, se celebra el Taller Subregional de Educación Ambiental para Educación Secundaria en Chósica, Perú, donde se comenzó a indagar las especificidades de la educación ambiental en los países en vías de desarrollo. También, entre los años 1976 y 1977, tienen lugar reuniones regionales de expertos intergubernamentales de educación ambiental en Brazaville (Congo) y en Bogotá (Colombia), donde se definió el papel de la educación ambiental como el instrumento de toma de conciencia del fenómeno del subdesarrollo y de sus implicaciones ambientales y señaló que la mayoría de los problemas ambientales detectados forman parte del cuadro general que se observa a escala mundial.

Para el año 1977, se desarrolló en Tbilisi, Unión Soviética, la Conferencia Intergubernamental de educación ambiental, organizada por la UNESCO y el PNUMA, donde se reconoció como vía idónea para la educación ambiental el enfoque interdisciplinario y como base para la resolución de problemas ambientales, elementos estos a un nivel teórico carentes, sin el accionar jurídico como elemento regulador, de la política del Estado. Aquí en Tbilisi, se aprecia cómo se amplió el concepto de medio ambiente y se establecen las pautas de actuación y prioridades para el futuro. Se concibió una política de información periódica para contribuir a la toma de conciencia, la que quedó incluida entre los objetivos del plan a mediano plazo de la UNESCO para 1977-1982; a partir de Tbilisi, se celebraron otras reuniones sobre la educación ambiental en ciudades como París (1978 y 1983), Belgrado (1980), Sofía (1985) y Moscú (1987), las que contribuyeron a la ampliación de la teoría relacionada con la educación ambiental.

En la década de los 80', continúan desarrollándose otros eventos; en 1983, comienza sus trabajos la Comisión BRUNDTLAND, con el objetivo de estudiar de modo interrelacionado los problemas ambientales del planeta. Una conclusión de ese informe es que resulta imprescindible 
vincular los problemas ambientales con la economía internacional y sobre todo con los modelos de desarrollo, de los mayores aportes de la comisión fue la sugerencia de retomar el modelo de desarrollo sostenible propuesto con anterioridad por el Club de Roma.

Para 1987, se desarrolló el Congreso Internacional de Educación Ambiental en Moscú, Unión Soviética, auspiciado por la UNESCO y el PNUMA, donde se proyecta la estrategia de acción en materia de educación y formación ambiental para el decenio 1990. En las conclusiones adoptadas se propone a los países que desarrollen sus propias estrategias de educación ambiental, para definir las finalidades se deben considerar las realidades económicas, sociales y ecológicas de cada sociedad y los objetivos que estas se hayan fijado para su desarrollo. Se planteó la necesidad aquí de ampliar el público objeto de este enfoque a la población en general, lo que sienta las bases para el surgimiento de la educación ambiental no formal o informal, concibiéndola como un sistema en el que se realimenten y apoyen. (Novo, 1985)

En la década de los 90', al concluir el siglo XX la crisis ambiental profundiza los problemas de deforestación, del cambio climático, del agotamiento de los recursos naturales, entre otros, a ello se le unen las hambrunas enormes, aumentan las migraciones humanas, crece la explosión demográfica y una deuda externa que sigue amenazando a los países del tercer mundo. En la ciudad de Talloires, Francia, en 1990, se realiza la declaración en la que lideres universitarios se comprometieron a realizar acciones transformadoras en los currículos universitarios y planes de estudio para el desarrollo sustentable. Declaración que fue reforzada en Halifax, Canadá en 1991, al aportarse en esta reunión el Plan de Acción.

Sobresalen entre las reuniones efectuadas en esta década concluyendo el siglo XX, en 1992, la Cumbre de la Tierra en Río de Janeiro, Brasil, con la participación de los Estados, donde se reconoce el derecho soberano a aprovechar sus propios recursos, según las políticas ambientales autóctonas. En este conclave se traza una estrategia internacional para la acción en el campo de la educación y formación ambiental para los años 1990-1999, y se aprobó en el Foro Global Ciudadano 
de Río 1992, el Tratado de Educación Ambiental hacia Sociedades Sustentables y de Responsabilidad Global, el cual parte de señalar a la educación ambiental como un acto para la transformación social, no neutro sino político, contempla a la educación como un proceso de aprendizaje permanente basado en el respeto a todas las formas de vida.

En 1993, en Kyoto, se convoca a promover la sostenibilidad ambiental a través de la educación ambiental. En 1994, la Declaración Copérnico, en Barcelona, se apostó por los valores ambientales tras un proceso de alfabetización. En 1996, se celebra la última gran cumbre de este siglo "Habitat II" en Estambul, Turquía, con el objetivo de discutir el futuro de la educación ambiental en el siglo XXI. Se reconoce el papel jugado por las organizaciones no gubernamentales en el desarrollo de la educación ambiental y en favor del medio ambiente en general, además, de la necesidad de hacer legislaciones globales a nivel de la ONU para la defensa del medio ambiente. Así, en 1997, en Tesalónica, Grecia, se apostó por incluir a la sostenibilidad ambiental, los conceptos de pobreza, población, seguridad alimentaria, derechos humanos, paz, salud, democracia, y el respeto a las tradiciones culturales ecológicas originarias. En Estocolmo en 1972, no se tuvo en cuenta la visión de las conductas aborígenes, quienes desde siempre han desarrollado actividades en armonía con el medio ambiente, con respeto al equilibrio natural.

En el año 2000, con el nuevo mileno, en Lüneburg, Alemania se acordó que la educación superior diera prioridad a temas sobre la sostenibilidad, pasando de la teoría a la práctica. Incidente que en pleno siglo XXI la educación es un desafío fundamental, y es el hecho de lograr una educación para toda la vida, concepción que abarca mucho más que las tradicionales como son la educación básica y la permanente. A partir del 2000, hasta la actualidad, se considera la existencia de una expansión de la educación jurídica ambiental al campo profesional. Las cumbres y conferencias ambientalistas efectuadas comienzan a converger, en el análisis de los problemas de la alimentación soberanía y seguridad alimentaria-, del cuidado al medio ambiente, del cuidado al patrimonio cultural, de poner límites a la tecnología y la extinción de la especie humana, del uso del agua, de las 
energías renovables, de ponderar los principios que desde el Derecho Ambiental informan, de implementar la fórmula estimulación/recompensa para hacer una sociedad más solidaria y humana a partir del control administrativo, con una serie de cuerpos jurídicos desde el Derecho Ambiental Internacional y desde el Derecho Público como parte de las políticas en los Estados, suscritos en Dakar 2000, en Johannesburgo en el 2002, y en Portugal en el 2004.

Por lo que se considera que la educación ambiental debe enfocarse a un paradigma que asuma el concepto de sistema para comprender y proyectar de manera más sostenible las relaciones entre el hombre y el medio ambiente ante el nuevo saber ambiental, -desarrollo sostenible-. Con una visión del ser humano asociado a su entorno, y del cual emerge una concepción ética enfocada hacia la vida de todos los seres vivos en el planeta. Uno de los mayores retos a los que se enfrenta la educación en el siglo XXI es el hecho de lograr un enfoque inter y transdisciplinario. Por ello, en Johannesburgo en el 2002, se escoge a la UNESCO para rediseñar y promover la educación ambiental.

Se considera, que los primeros aportes de sistematización conceptual y metodológica comienzan a gestarse entre las reuniones realizadas en Estocolmo, Belgrado y Tbilisi, siendo esta última la de especial importancia para la difusión internacional de la educación ambiental. En ellas, se aprecia cómo se fijaron principios innovadores e inéditos para la problemática educativa contemporánea, como la ética de la sustentabilidad y el abordaje del mundo como un sistema complejo, impregnado con el hálito de la interdisciplinariedad. En la interdisciplinariedad se reparten las tareas, al tener que trabajar conjuntamente en un proyecto o problema, sin tener que entrar a entender o cuestionarse las disciplinas entre sí, sino cada una se puede quedar dentro de sus conceptos y métodos.

La educación ambiental, como disciplina tiene que tener un enfoque integrador, holístico e interdisciplinario, donde se articulen los conocimientos, la información y los saberes locales; de la misma manera, debe contemplar una visión ética, política y pedagógica que proporcione elementos 
teóricos y prácticos para establecer, fundamentar y enriquecer los conocimientos en esta área. (Osorio, M. 2015).

Con esta medida, se considera que se impone la necesidad de que las reglas de protección ambiental tengan realmente alcances internacionales, para cuyo fin deben actuar los sectores gubernamentales y académicos. Las normas internacionales de protección ambiental se han ocupado, por varios años, en diversos foros de discusión y creación jurídica, mediante la adopción de tratados internacionales con finalidades de preservación ambiental, y por medio de políticas internacionales han fortalecido el proceso de formación de la costumbre internacional en materia ambiental, aunque aún su respuesta no sea la esperada en pos de mitigar los adversos ambientales, al decir por diversos autores que es "soft law" (Antúnez, 2018)

En América Latina y el Caribe, este proceso formativo se distingue al crearse la Red de Formación Ambiental por el PNUMA y la UNESCO, conocida como "Carta de Bogotá", ello impulsó el pensamiento ambiental en la región, y condicionó la creación de nuevas carreras ambientales como la de Ciencias Ambientales con el Ingeniero Ambiental dentro de su perfil, entre las carreras de corte ecológico que fueron diseñadas. Un referente desde la academia en la región Latinoamericana, han sido los aportes de LEFF, (2006), reconocido como pionero del ambientalismo en la región, quien ha centrado su obra en la epistemología ambiental y la ecología política, como impulsor de procesos institucionales y movimientos sociales en favor de la educación ambiental en América Latina y el Caribe, este autor hace un análisis profundo de la complejidad ambiental desde una perspectiva crítica y analítica, rebasando los discursos políticos en pos de proteger el medio ambiente. Refiere este autor consultado que, en la región, en el desarrollo de programas de investigación y formación ambiental ha sido lento. En ello se conjugan una serie de causas, desde los obstáculos epistemológicos ante los que se enfrenta la constitución de nuevos paradigmas ambientales, las barreras institucionales y los intereses disciplinarios en los que se desarrollan las prácticas académicas. El logro de estos objetivos plantea dentro de las políticas publicas retos teóricos, 
académicos e institucionales para lograr el avance de la formación ambiental en la región, aun sin consolidarse, por esta cuestión se le señala como uno de los paradigmas en el siglo XXI a la academia.

La formación ambiental plantea la necesidad de generar y sistematizar un saber ambiental que pueda ser incorporado a nuevas estructuras curriculares y practicas académicas capaces de preparar a un nuevo profesional para abordar los problemas ambientales de su disciplina desde con una preparación más comprehensiva de orden teórico y práctico, ello sigue siendo un reto por alcanzarse. Existen un conjunto de saberes prácticos y una serie de técnicas de evaluación y monitoreo ambiental sistematizados, las que pueden ser incorporadas a diferentes cursos, cátedras y carreras. Los saberes técnicos especializados, como las técnicas de monitoreo del aire, el análisis y tratamiento de las aguas, del reciclaje de los desechos, los sistemas de información geográfica, es una necesidad incorporarlos a las carreras, como a las metodologías de evaluación de impacto ambiental, sobre el control público ambiental, las que deberían ser incorporadas a las carreras y a proyectos de desarrollo. Un ejemplo de ello es la función inspectiva y la auditoria desde la dimensión ambiental, para lograr el alcance con empresas públicas y privadas competitivas en los mercados. (Antúnez \& Ramírez, 2016).

Las aplicaciones de las nuevas tecnologías a la gestión ambiental (biotecnología, microelectrónica, teledetección y nuevos materiales), y los desarrollos de las fuentes alternativas de energía renovables y las no contaminantes, deberán incorporarse a la formación ambiental. Por la pertinencia de ponderar el principio de prevención y precaución, sin desdeñar el de legalidad. La cuestión ambiental plantea a la Universidad la necesidad de ubicarse en las transformaciones sociales hacia el desarrollo equitativo, democrático y sustentable. Por ello, el autor de este ensayo pondera que será un valor añadido tener un egresado formado en temas ambientales en la empresa pública, los que con la aplicación de la hipercultura jurídica permitirá una mayor socialización e irradiación en las redes sociales con el uso de las Tic (Antúnez, 2018). 
De aquí, que se hable hoy de una pedagogía transformadora, como un término provocador en los tiempos que corren, que pretende ser un camino de descubrimiento y transformación, se relaciona directamente con el de saber ambiental. El documento de la UNESCO, denominado Replantear la educación. ¿Hacia un bien común mundial? (2015), destaca el papel de la educación como el elemento fundamental de marco mundial integrado de los objetivos de desarrollo sostenible, destaca la necesidad de transformación de la educación adecuándola a los cambios y retos de los contextos actuales, con enfoques que generen una mayor justicia, la equidad social y la solidaridad mundial, considerándola como la herramienta más valiosa de transformación de las sociedades. El mundo en el siglo XXI está obligado a desaprender para reaprender a aprender sobre la relación dialéctica entre naturaleza, sociedad y política. (RonCAL, X. 2015).

Lo sistematizado, permite afirmar que lo acontecido es un hito importante en la educación ambiental, a partir del nacimiento de su dimensión jurídica. Entonces, puede afirmarse que, a partir del análisis histórico, el desarrollo de la sociedad cubana en la actualización de su modelo económico social, exige a la Universidad que sus egresados alcancen una amplia cultura general, ambiental y tecnológica, que le permita insertarse en el proceso productivo dentro del desarrollo de la empresa pública con mayor autonomía.

A su vez, este desarrollo se caracteriza por los constantes cambios que se producen, generados por el desarrollo de la revolución científico técnica en el siglo XXI. Empero, aunque se observan progresos en la universalización de las actividades relativas a la protección del medio ambiente, es necesario señalar que el contenido de los programas de educación ambiental ha girado demasiado en torno a elementos cognoscitivos teóricos en detrimento de lo axiológico y lo técnico, que ocupan todavía un espacio reducido en la práctica profesional, ello sigue siendo un reto por alcanzarlo y desarrollarlo en los planes de estudios por los profesores de manera integradora y no fragmentada. 
Como un hecho social, la educación jurídica ambiental salió de las Escuelas de Derecho y puede colegirse que comenzó a penetrar el campo profesional por la acción de la ciencia y la tecnología sobre el medio ambiente, pero el enfoque interdisciplinario sigue siendo un objetivo por alcanzarse de manera adecuada en el sistema educacional y no verlo de manera fragmentada, en pos del desarrollo sostenible como política pública en pos de lograr alcanzar el desarrollo sostenible. Contextualizado en la aplicación del control público ambiental dirigido a los actores económicos. (RAMÍREZ \& ANTÚNEZ, 2016).

Pero, a pesar de los esfuerzos realizados, la demanda de material didáctico necesario para introducir la educación ambiental en los procesos educativos sigue siendo un tema importante en todas las regiones del mundo y constituye una de las prioridades permanentes para la acción de los Estados en el campo de la educación ambiental, con el nuevo saber ambiental, el desarrollo sostenible. Se aprecia con ello, que las tendencias ambientalistas actuales tienden a develar la complejidad intrínseca del problema epistemológico, por ello la diversidad de conceptualizaciones de la problemática ambiental han incluido su definición como problema científico particular (problema de la relación de la sociedad-naturaleza); problema de economía y política (problema político y económico de la relación de la sociedad con la naturaleza); problema de cultura y civilización (problema de la relación de cierto tipo de sociedad y cultura con la naturaleza).

La formación ambiental, se justiprecia que es uno de los principales desafíos del quehacer de las Uuniversidades, esta debe estar orientado hacia la necesidad de formar profesionales capaces de operar cambios en el comportamiento de la sociedad en su conjunto, así como de la transformación del conocimiento y la innovación de tecnologías para la solución de los problemas ambientales, e introducir el nuevo saber ambiental, el desarrollo sostenible.

Las concepciones sobre educación y formación ambiental según la posición de LEFF (2000), y demás investigadores de este movimiento educativo en el mundo, resultan acertados en el contexto de la formación ambiental; en tanto, el proceso de formación del profesional, bajo las condiciones 
histórico-concretas actuales, está orientado a la creación de una cultura ambiental para el desarrollo sostenible, para que se minimicen los problemas generados al medio ambiente desde su modo de actuación profesional.

Sin embargo, se aprecia que paralelamente al extraordinario progreso científico y tecnológico, el que ha permitido un alto nivel de vida en las sociedades desarrolladas hoy más que nunca se advierten los innumerables riesgos originados por el propio desarrollo tecnológico y sobre los que, pese a dicho progreso sigue presente la incertidumbre científica sobre los efectos al medio ambiente y a la salud humana, necesitados de una adecuada formación jurídica ambiental como valor añadido para la empresa responsable con el ambiente, y en este sentido en el operador jurídico tiene incidencia con sus conocimientos en la materia ambiental adquiridos desde la academia, toda vez que debe ponderar los principios del Derecho Ambiental y del Derecho Administrativo. (Antúnez Sánchez, 2015).

MARTín (1991), en sus estudios sobre el mega principio -desarrollo sostenible- considera: el sector privado (incluidas las grandes empresas y las pequeñas) tiene el deber de contribuir a la evolución de comunidades y sociedades equitativas y sostenibles (Principio 24), y que las empresas del sector privado deben cumplir la obligación de rendir cuentas, en un entorno reglamentario, transparente y estable (Principio 26).

Queda claro que, es una necesidad alcanzar el desarrollo sostenible en el siglo XXI, el Informe "Nuestro Futuro Común" así lo señala desde el siglo pasado, el paradigma es cómo establecer políticas públicas para concretarlo. En ello, la educación ambiental, como obligación pública deber-derecho, obedece a esta misma lógica de hacer efectiva una responsable participación de la ciudadanía en las decisiones de naturaleza ambiental, para participar es necesario estar informado como estar formado, de aquí la necesidad de la formación ambiental, que desde las cartas políticas se reconoce el derecho a la educación. 
El concepto de formación ambiental, en el Programa de las Naciones Unidas para el Medio Ambiente (1982), enfatiza este proceso como: ..."un conjunto de actividades teóricas o prácticas que llevan a una más adecuada comprensión de los problemas ambientales y a un entrenamiento técnico (capacitación), para el manejo de los ecosistemas, en función de una adecuada calidad de vida"...

Se valora, que la concepción de la educación ambiental, orientada a la preservación de la naturaleza, es la primera etapa de la evolución histórica de este movimiento, estuvo enfocada hacia la capacitación técnica para comprender los problemas ambientales y actuar sobre el manejo adecuado de los ecosistemas para alcanzar el desarrollo sostenible. En este íter, las Naciones Unidas declararon el decenio 2005-2014, como la Década de la Educación para el desarrollo sostenible, en la que se revela entre los principales objetivos: “[...] la integración de valores inherentes al desarrollo sostenible en todos los aspectos de la enseñanza [...] mediante todas las formas de educación”.

Se infiere de dichos objetivos, la necesidad de formar en la mente de las personas, una manera nueva de asumir el medio ambiente, la cual debe estar dirigida al desarrollo de los valores, que le permitan al individuo participar de forma activa, protagónica y consciente en la sostenibilidad del desarrollo. Pero para ello, debe estar informado de los problemas ambientales de su entorno. Por consiguiente, comprender el principio del desarrollo sostenible, a criterio del autor de este ensayo, resulta un proceso complejo y para ello la educación ambiental como sistema ha de asumir la responsabilidad de conducir los valores y la apreciación tanto individual como colectiva del mismo, que desde el Derecho Ambiental se establecen. Ello es un paradigma para las universidades en el siglo XXI por lograr alcanzar en el proceso de formación ambiental.

En el posicionamiento teórico, se valora el desarrollo sostenible y no el de desarrollo humano sostenible; sin embargo, lo importante es el hecho que precisa que la educación jurídica ambiental no está referida solamente a la legislación, sino también a discernir sobre lo justo y lo injusto, lo legal e ilegal, lo legítimo o no, que hace que constantemente el jurista esté estudiando, indagando sobre las 
necesidades del desarrollo humano sostenible y las leyes que lo respaldan, de forma contextualizada para integrar conocimientos. Por consiguiente, universalizar el conocimiento es una premisa indispensable para alcanzar el desarrollo sostenible, implica igualdad de oportunidades, equidad, justicia social y por sobre todas las cosas, responder a las necesidades de estudio y superación, sin límite alguno, de toda la población. En esencia, significa educación para todos durante toda la vida. Dos puntos son indispensables para el desarrollo sostenible:

Primero, comprender que el crecimiento económico solo no basta para resolver los problemas del planeta: los aspectos económicos, sociales y ambientales de cualquier actividad están vinculados. Considerar únicamente uno de ellos a la vez da por resultado errores de juicio y de resultados insostenibles. Concentrarse sólo en los márgenes de utilidad, por ejemplo, históricamente ha causado daños sociales y ambientales que en el largo plazo le cuestan a la sociedad. Pero cuidar del medio ambiente y proporcionar los servicios que necesita la ciudadanía depende de los recursos económicos, al menos en forma parcial.

Segundo, la naturaleza intervinculada del desarrollo sostenible requiere que se trasciendan fronteras, ya sean geográficas o institucionales, para coordinar estrategias y tomar decisiones adecuadas. Los problemas rara vez están circunscritos a jurisdicciones definidas previamente como una dependencia del gobierno o un vecindario particular; y las soluciones inteligentes exigen que haya cooperación como parte del proceso decisorio.

En el núcleo del desarrollo sostenible está la necesidad de considerar tres pilares juntos: la sociedad, la economía y el medio ambiente.

En este plano, la idea fundamental del desarrollo sostenible es la vinculación entre el bienestar de la generación actual y el bienestar de las futuras generaciones. En ello, se aprecia que los sistemas de valores no han tomado en cuenta a la naturaleza y se han desbocado en una irracional carrera por el consumismo como estilo de vida y desarrollo sin una adecuada responsabilidad ambiental. El reto es desarrollar una sociedad ante los desafíos que se presentan para lograr el 
desarrollo sostenible como ... “aquel que satisface las necesidades esenciales de la generación presente sin comprometer la capacidad de satisfacer las necesidades esenciales de las generaciones futuras" ...

También, en interés del ensayo, se hace necesario particularizar la concepción desarrollada en su postura por LEFF (2000), el cual concibe la ética ambiental con un enfoque integrador de las dimensiones del medio ambiente y destaca que esta responde al conjunto de principios y valores en la conducta humana que establece la autodeterminación y autoconfianza del individuo para conservar y mejorar la calidad ambiental y los recursos naturales.

Nos afiliamos a la postura de LEFF (2006) quien señala que ... "La historia ha dibujado a un hombre que enfrentó a la naturaleza, en la actualidad emerge la necesidad de un hombre ecológico que comparta los poderes tecnológicos que ha logrado con una racionalidad diferente, con una inteligencia inclinada hacia la preservación y cuidado de sí mismo desde el medio natural que es él mismo en otra dimensión. Nos encontramos en un momento en que el pensamiento se identifica con un estado de “...inflexión de la historia que induce una reflexión sobre el mundo actual de donde emergen las luces y las sombras de un nuevo saber" ...

Es preciso sentar posición sobre el Derecho Ambiental, como parte del sistema jurídico y rama de las ciencias jurídicas, cuyo origen se ubica en la década de los 70', del siglo pasado a partir de la Cumbre en Estocolmo, desde aquí se comienza a introducir la normativa ambientalista en el ordenamiento jurídico de un gran número de países, siendo el punto de conexión con el Derecho Internacional. Al que también se le denomina Derecho del Medio Ambiente o Derecho Ecológico, definido por diferentes autores desde perspectivas distintas como MARTIN (1991); BRAÑES (2001); Ortega, L. (2002); CAferrata, (2004); De Besa (2011), entre otros que han abordado esta temática.

Es un suceso jurídico que, el Derecho Ambiental, se caracteriza por tener relaciones con otras ramas del Derecho, donde esta interrelación de carácter dialéctico, le aportan elementos que 
desarrollan tanto del Derecho Ambiental, como al resto de las ciencias jurídicas que se relacionan con él. En el se regula las conductas humanas con implicaciones ambientales, se recogen conocimientos científicos que se han generado en el Derecho Internacional como su génesis, con el Derecho Constitucional como asidero principal, y con el Derecho Administrativo, Derecho Mercantil, Derecho Económico, Derecho Civil, Derecho Laboral, Derecho Financiero Tributario, Derecho Agrario, Derecho de la Propiedad Industrial, Derecho Penal, entre otras; confiriéndosele una lectura distinta a la que otras ramas del Derecho pudieron haber hecho de los mismos, y luego de haberle dado el alcance que le corresponde, de acuerdo con su objeto los combina para formar un cuerpo nuevo y unificado que se materializan en el conjunto de categorías reguladas en el sistema normativo ambiental de una nación.

Aún y cuando el Derecho Ambiental se manifiesta a través de los actos jurídicos que le son propios, mucha de su normativa se encuentra dispersa en el resto de las ramas que conforman el sistema jurídico. Lo que se justifica atendiendo a que ninguna norma jurídica pertenece de una manera exclusiva y excluyente a una rama del Derecho determinada, consideradas bajo diferentes enfoques que son válidos tanto para el Derecho Ambiental como para otras disciplinas jurídicas que la contengan, pues no resulta factible fijar exactos límites entre ellas; realmente puede existir una zona común en sus fronteras (CAÑIZARES, F. 1998).

JACQUENOD (2001), considera al Derecho Ambiental como ... "la disciplina jurídica que investiga, estudia y analiza las diferentes relaciones entre los bienes naturales y la actividad antrópica, orientando la relación jurídica de las conductas y actitudes humanas respecto al uso, explotación y aprovechamiento de recursos naturales, conservación de la naturaleza y protección del medio ambiente" ... En este mismo íter, JAQUENOD (2015) sigue señalando en este sentido que: ... "sería aventurado afirmar que el derecho ambiental se perfila como una rama autónoma del ordenamiento jurídico, puesto que éste es un sistema de normas que no admite la existencia de regímenes totalmente separados; por tanto, adquiere relevancia en la medida en que se integra a un 
circuito de normas, a una interconexión progresiva de preceptos cuyo principio y fin es la construcción" ... Además, señala esta autora que tampoco podría decirse que forma parte de una rama especial del Derecho Público, ya que es difícil mantener la tradicional separación entre el régimen jurídico público y el privado debido a la infiltración de las instituciones jurídico-públicas en el régimen que rige las relaciones entre los particulares, y a una privatización de las reglas que presiden la organización y funcionamiento del Estado y sus instituciones.

Para JAQUENOD (2015), el Derecho Ambiental es definido como la disciplina jurídica que investiga, estudia y analiza las diferentes relaciones entre los bienes naturales y la actividad antrópica, orientando la regulación jurídica de las conductas y actitudes humanas respecto al uso, explotación y aprovechamiento de recursos naturales, conservación de la naturaleza y protección del ambiente Algunos autores consideran que el Derecho Ambiental es una rama autónoma del Derecho, debido a que cumple con los requisitos que suelen apuntarse como necesarios para considerar que una disciplina es autónoma.

A su vez, JORDANO (2011), considera que el Derecho Ambiental tiene requisitos, estos son los siguientes: presencia de principios propios, que existan técnicas jurídicas propias, referencia a determinada categoría de personas, de objetos o de relaciones. Señala que para formular un concepto de esta disciplina jurídica se puede partir de dos facetas: desde una perspectiva teleológica o funcional del derecho, desde una perspectiva que responda a un análisis estructuralista y jurídicoconstitucional. Por ello el Derecho Ambiental tendría que ser estudiado a partir de la Constitución. Así, en el ordenamiento jurídico, el Derecho Ambiental, desde esta perspectiva estructuralista y jurídico-constitucionalista, se presentaría como el derecho que concede la garantía individual, que consagra el derecho que toda persona tiene a disfrutar de un medio ambiente adecuado para su desarrollo y bienestar.

En este sentido, para MARTIN (1991) quien señala, que este derecho reúne una serie de características que le son propias y que permiten determinarlo como tal. Refiere que tiene un sustrato 
ecológico, una especialidad singular, un énfasis preventivo, un componente técnico-reglado, una vocación redistributiva, hay primacía de los intereses colectivos, es multidisciplinar, su mixtura normativa reconoce lo antiguo y lo nuevo, y es trasnacional.

A la vez este autor consultado, señaló que el Derecho Ambiental se encuentra lejos de su madurez, si es que puede alcanzarla algún día dada su íntima conexión con una problemática científica que dista de estar resuelta, el cual, según su versión, incluye... "los elementos naturales de titularidad común y de características dinámicas: en definitiva, el agua y el aire, vehículos básicos de transmisión, soporte y factores esenciales para la existencia del hombre sobre la tierra. Puede pensarse también que entre tales elementos cabría incluir el suelo, como efectivamente parece entender la Administración Ambiental americana, ... pero creemos que la gestión del suelo o bien reconduce a la ordenación global del territorio y a la lucha contra la erosión con trascendencia más amplia que la propia gestión ambiental, o a la postre, se conecta con los ciclos del agua y del aire, bien en cuanto sustancias depositadas en el suelo y que en aquellos se transportan, bien en cuanto a eventuales alteraciones de estos ciclos al perturbarse las condiciones meteorológicas, por obra, por ejemplo de la deforestación.

Por su parte, LORENZETTI (2013), parte de señalar que el paradigma ambiental reconoce como sujeto a la naturaleza, que es un bien colectivo, lo define como escaso o en situación de peligro y está dispuesto a limitar los derechos individuales. El ambiente es un "macro-bien", y como tal es un sistema, lo cual significa que es más que sus partes: es la interacción de todas ellas. Los "microbienes" son partes del ambiente, que en sí mismos tienen la característica de subsistemas, que presentan relaciones internas entre sus partes y relaciones externas con el macro-bien. En esta categoría subsume a la fauna, la flora, el agua, el paisaje, los aspectos culturales, el suelo, etc. La biodiversidad, por ejemplo, es un micro bien, que tiene relaciones internas con todos los aspectos que la integran, pero, asimismo, es un asunto horizontal que influye y está presente en varios de los otros 
micro bienes, como la flora y la fauna. El bien ambiental es colectivo, situado en la esfera social y que causa tanto derechos como obligaciones.

Señala este autor consultado ... "El Derecho Ambiental es descodificante, herético, mutante: "se trata de problemas que convocan a todas las ciencias a una nueva fiesta, exigiéndoles un vestido nuevo. En el caso del Derecho, la invitación es amplia abarca lo público y privado, lo penal y lo civil, lo administrativo, lo procesal, sin excluir a nadie, con la condición que se adopten nuevas características" ...

De aquí que se pondere la necesidad de lograr una educación jurídica ambiental como una dimensión de la educación ambiental, al ser un proceso continuo y permanente orientado al conocimiento generalizado de los derechos y de las obligaciones que, en el proceso de construcción y producción de conocimientos, de desarrollo de hábitos, habilidades, y actitudes, así como en la formación de valores jurídicos, armonice las relaciones entre los seres humanos, y de ellos con el resto de la sociedad y la naturaleza, sobre la base de las categorías de lo justo y lo injusto, lo legal e ilegal, lo legítimo o no que pueden ser estas relaciones en un contexto histórico determinado, para propiciar la orientación de los procesos económicos, sociales y culturales hacia el desarrollo sostenible (MUÑOZ, 2008).

Por su parte, TORANZO (2008), en su aporte define la educación jurídica ambiental como ..."proceso de educación ambiental que integra el contenido de las categorías jurídicas relacionadas con el medio ambiente, donde se establece una dialéctica entre deberes y derechos que generen un conocimiento jurídico del alumno hacia el medio ambiente, relación que permite sensibilizarse ante los problemas ambientales y por consiguiente una disposición favorable hacia el cumplimiento de lo legislado en virtud de ejercer la ciudadanía plena” ...

La autora consultada, concibe la formación jurídica ambiental como una cualidad que emerge de la formación jurídica y a la formación ambiental del estudiante. Esta es una definición de carácter general para la formación ciudadana en esta materia, no se relaciona con una profesión, por lo que no 
se aviene en su totalidad al objeto de esta investigación. Además, se queda en el orden de sensibilizar y no del actuar.

La educación jurídica ambiental busca la formación de una cultura jurídica ambiental, sin embargo, las ciencias de la educación no se han ocupado de este aspecto en profundidad de manera adecuada; no obstante, sobre cultura jurídica o cultura de la legalidad se ha particularizado el conocimiento de los derechos y de las obligaciones, de las prácticas y costumbres a las que se les atribuyen en algunos sistemas de derecho una función razonable y relevante en la vida colectiva, que permita dar cumplimiento al principio de legalidad, el que desde el Derecho Público se pondera. EsCASENA (1990); MATILla, et al (2017)

Es evidente que la educación jurídica ambiental ha sido entendida como el proceso en el cual la sociedad civil forma parte activa, consciente y creadora de las decisiones que afectan su entorno ambiental y social y en función de alcanzar una adecuada calidad de vida y de sustentabilidad. Esto implica la incorporación activa en la dinámica del quehacer cotidiano, la elaboración de alternativas para la resolución de problemas de la comunidad, la motorización de procesos de información y sensibilización hacia el resto de la comunidad, el conocimiento y cumplimiento de los deberes y derechos de los ciudadanos y el fortalecimiento de las formas organizativas como instrumentos de participación. Esta participación debe ser entendida como la intervención activa en todo el proceso social, desde la identificación de necesidades, la consecuente definición y formulación de políticas, hasta la ejecución, pasando por la implementación y control del desarrollo de la actividad en torno a dichas políticas.

Lo explicado apunta, la educación jurídica ambiental debe desarrollarse permeando la misión de la Universidad, sea, resguardar, divulgar y desarrollar la cultura jurídica ambiental y no quedarse el jurista solamente vinculado a las leyes, según se dispone en el Capítulo 36, de la Agenda 21: ..."La educación es de importancia crítica para promover el desarrollo sostenible y aumentar la capacidad de las poblaciones para abordar cuestiones ambientales y de desarrollo, de acuerdo con los 
preceptos de la ONU, para ser eficaz, la educación en materia de medio ambiente y desarrollo debe ocuparse de la dinámica del medio físico y biológico, y del medio socioeconómico y el desarrollo humano (que podría comprender el desarrollo espiritual), integrarse a todas las disciplinas y utilizar métodos académicos y no académicos y medios efectivos de comunicación..."

En el ámbito de la educación jurídica ambiental, cobran importancia los trabajos teóricos de ZELEDÓn ZELEDON (2001), quien, sobre Derecho Ambiental en el contexto de Latinoamérica, le reconoce como un entramado complejo de doctrinas, que se va constituyendo como un conjunto de derechos que atraviesa a todo el sistema jurídico, tanto en su racionalidad formal como en sus bases materiales, en sus principios axiológicos y en sus instrumentos normativos. Ello demanda una transformación profunda del régimen jurídico que sostiene a la racionalidad económica dominante; implica una movilización de la verdad que fragua en nuevos fundamentos y formas jurídicas.

Desde el plano jurídico, se pondera que estos elementos abordados son reforzados con el reconocimiento jurídico del pluralismo jurídico De Jure, al otorgarse derechos a la naturaleza como sujeto, la pacha mama dentro del sumak kuasay en Bolivia y Ecuador en la región de América Latina, como referentes en sus cartas políticas de este siglo XXI, lo diferencian con otras naciones donde el Derecho Ambiental tiene un mayor desarrollo dentro del concepto del buen vivir. (VILlaVella, 2012); (RodRÍGUEZ, 2016); (ANTÚNEZ \& DÍAZ, 2018)

ZAFFARONI (2011), afirma sobre la tendencia manifiesta en estas dos Constituciones, que ... "la Tierra asume la condición de sujeto de derechos, en forma expresa", añadiendo que "de este modo el constitucionalismo andino dio el gran salto del ambientalismo a la ecología profunda, es decir, a un verdadero ecologismo constitucional. La invocación de la Pachamama va acompañada de la exigencia de su respecto, que se traduce en la regla básica ética del sumak kawsay, que es una expresión quechua que significa buen vivir o pleno vivir y cuyo contenido no es otra cosa que la ética-no la moral individual- que debe regir la acción del estado y conforme a la que también deben relacionarse las personas entre sí y en especial con la naturaleza (...) No se trata del tradicional bien 
común reducido o limitado a los humanos, sino del bien de todo lo viviente, incluyendo por supuesto a los humanos, entre los que exige complementariedad y equilibrio, no siendo alcanzable individualmente"...

Lo anterior implica, la necesidad de construir un nuevo concepto de naturaleza, superar su imagen cosificada como res extensa instaurada por el derecho positivo moderno; de una naturaleza susceptible de ser manipulada, sometida, dominada, controlada, explotada. Se trata de sustituir los principios inconmovibles e inamovibles del Derecho Privado, por un proceso abierto al juego de valores e intereses sobre la conservación, uso y transformación de la naturaleza, con procedimientos jurídicos flexibles para dirimir conflictos de intereses contrapuestos y para alcanzar un bien público basado en el reconocimiento de sus diferencias.

El Derecho Ambiental, no es sólo el conjunto de normas que aseguran el uso controlado de la naturaleza, sino aquel que regula los intereses en conflicto en torno a las estrategias diferenciadas de apropiación de sus recursos, donde se inscriben los derechos territoriales y culturales de los pueblos. El derecho a un ambiente sano es fundamental porque es humano. Significa que su valor fundamental no tiene fuente distinta a su consustancialidad con el ser humano, que, forjado en un crisol de avatares biológicos, históricos, sociales y axiológicos, irremediablemente perdería su condición humana si fuese despojado de sus derechos fundamentales, a partir de su reconocimiento entre los derechos de solidaridad. BRAÑES (2001); BELLORIO \& RINALDI (2013).

Lo analizado, permitió reconocer que la educación jurídica ambiental es vista como un proceso educativo que integra el contenido de las categorías jurídicas relacionadas con el medio ambiente, donde se establece una dialéctica entre deberes y derechos que generen un conocimiento ético-jurídico del estudiante hacia el medio ambiente, relación que permite sensibilizarse ante los problemas ambientales y poseer herramientas para cumplir y hacer cumplir lo regulado en los ordenamientos jurídicos en virtud de ejercer la conservación del entorno natural y social. Por su 
transversalidad integra conocimientos desde la Contabilidad, las Ciencias Ambientales, la Biología, la Geografía, la Física, la Química, las Matemáticas, la Informática, entre otras. (ANTúnEZ, A. 2018)

Desde la perspectiva anterior, LEFF (1980), como cimiento teórico ha considerado ..."la necesidad de internalizar un saber ambiental emergente en todo un conjunto de disciplinas, tanto de las ciencias naturales como sociales, para construir un conocimiento capaz de captar la multi causalidad y las relaciones de interdependencia de los procesos de orden natural y social que determinan los cambios socio ambientales, así como para construir un saber y una racionalidad social orientada hacia los objetivos de un desarrollo sustentable, equitativo y duradero"...

\section{El desarrollo sostenible, reconocimiento en el ordenamiento jurídico cubano}

En el año 1958, desde el pasado siglo ÁLVAREZ CONDE, se acercó en sus estudios ambientales a lo que hoy se define como desarrollo sostenible. Aunque, el surgimiento del Derecho Ambiental en Cuba no se pueda ver identificado con factores de fácil apreciación, como así lo considera desde sus estudios CARABallo (2007); REY et al (2017).

El triunfo de Revolución Cubana en 1959, implicó mejoras ambientales pese a lo heredado; la erradicación de la pobreza y sus secuelas en términos de la salud y educación; las mejoras de las condiciones ambientales y calidad de vida en un marco de equidad; el incremento de la superficie boscosa nacional, la declaración progresiva de áreas protegidas y parques nacionales; el trabajo sistemático de ordenamiento territorial y de evaluación ambiental de las inversiones priorizadas; el uso de las capacidades científicas en el diagnóstico y el desarrollo de tecnologías para la solución de muchos problemas del medio ambiente; el proceso de introducción progresiva de la dimensión ambiental en el Sistema Nacional de Educación aparejado al crecimiento de la gestión ambiental nacional entre otros.

El proceso revolucionario, al concluir el $1{ }^{\text {er }}$ Congreso de Partido Comunista de Cuba en 1975, y superada la etapa de provisionalidad institucional al amparo de la Constitución Socialista de 1976, 
se crea el Ministerio de Educación Superior, en pos de dar cumplimiento a la formación de profesionales en la nación cubana dentro del entramado de la Administración Pública. En el ordenamiento jurídico cubano, se le otorga rango constitucional al medio ambiente en la Constitución de la República de Cuba de 1976, modificada en 1992, en su artículo 27, plantea como principio fundamental "la protección estatal del Medio Ambiente y los recursos naturales por su estrecha vinculación con el desarrollo económico y social sostenible para hacer más parcial la vida humana y asegurar la supervivencia, el bienestar y la seguridad de las generaciones actuales y futuras"

En este ámbito, se aprecia como la reforma constitucional realizada en 1992, entre otros aspectos, vino a reformular el artículo 27, el que consagra el deber del Estado y de todos los ciudadanos de la preservación del medio ambiente. Partiendo de lo establecido en el artículo 27, de la Constitución de la República, se puede plantear que, al reconocer dicho texto una obligación general para el Estado y los ciudadanos, el mismo se consagra el derecho a un medio ambiente sano como un derecho constitucionalmente protegido, elevado a la categoría de principio configurativo del ordenamiento político y jurídico. La Constitución de la República de Cuba de 1976, con sus sucesivas reformas en 1978, 1992, y 2003, no se reconoce de forma explícita el derecho a un medio ambiente sano, o equilibrado, tal como se define en otros ordenamientos foráneos. Esta es una de las falencias que cabe señalar al texto constitucional cubano, al menos en el orden formal. Aunque si ha sido una de las primeras naciones en reconocer el desarrollo sostenible en su carta política en América Latina. Aunque vale recordar que, aun cuando se lograse un reconocimiento expreso, tal como es de desear, el objetivo de tutela ambiental no se alcanzaría, pues ese derecho a un medio ambiente sano ha de traducirse en el reconocimiento a unas facultades concretas, que debe desarrollar posteriormente en la legislación ordinaria dentro del ordenamiento jurídico, tal y como lo señala CÁNOVAS (2012), con el cual se coincide. 
No cabe duda que, aquí se consagra la protección ambiental como función pública. Técnicamente, a la vez que se habilitaron los órganos competentes para intervenir en la protección ambiental inspirados en el desarrollo sostenible, se ordenó la aplicación de dicha habilitación con el objetivo de hacer más racional la vida humana y asegurar la supervivencia, el bienestar y la seguridad de las generaciones actuales y futuras, con lo que la solidaridad en términos de equidad inter e intrageneracional, la racionalidad y la sostenibilidad trascienden al texto constitucional. Como se aprecia, el Estado cubano estableció un modelo institucional nuevo, sustentado en una instancia coordinadora de gestión ambiental, coexistiendo con la distribución de competencias previas respecto a los recursos naturales y a los sub sistemas ambientales, rectorados por el Ministerio de Ciencias, Tecnología y Medio Ambiente, cuando se creó dentro de los organismos de la Administración Publica en la década de los 90', del siglo pasado.

Por ello, la función pública ambiental cubana, ejecutada por los servidores públicos, se complementa con la declaración de soberanía estatal sobre los recursos naturales y el medio ambiente, proclamada en el artículo 11, del texto constitucional en unión a los artículos 10 y 27. Estos artículos conforman las bases constitucionales fundamentales que validan la práctica del control público para proteger el ambiente con observancia de la legalidad. Reproducen el principio del desarrollo económico y social sostenible contenido en los principios 3 y 4, de la Declaración de Río de Janeiro de 1992, como bien público tutelado. Entonces, afirmar que el derecho a un medio ambiente sano es un derecho fundamental significa que no se concibe que la persona pueda desenvolverse plenamente sin disfrutar de un entorno adecuado que le permita desarrollar todas sus potencialidades. No hay vida digna sin un medio ambiente adecuado. De ahí que se pueda sostener el estrecho vínculo existente entre el derecho a un medio ambiente sano y otros derechos esenciales como el derecho a la vida, pues este incluye no sólo la realización de las diferentes funciones vitales, sino una vida con calidad. 
Igualmente, no habrá salud verdadera, y por tanto derecho a la salud, sin un entorno sano, que, en sus cualidades físicas o químicas, o en la diversidad biológica presente en él, permita al ser humano la consecución de los fines más altos. En palabras de la Declaración de Río sobre Medio Ambiente y Desarrollo: "Los seres humanos constituyen el centro de las preocupaciones relacionadas con el desarrollo sostenible. Tienen derecho a una vida saludable y productiva en armonía con la naturaleza”. El derecho a un medio ambiente sano es, pues, hasta tal punto esencial para la existencia de otros derechos, que debe tener carácter preferencial con relación a ellos. Ante la ocurrencia de una colisión de derechos, en la que el derecho al ambiente se enfrente a otros, sobre todo aquellos de índole económica o social, debe prevalecer el derecho a un medio sano, como presupuesto que es para el ejercicio pleno de los otros derechos. Muchos de los derechos civiles y políticos, y algunos otros como el derecho a la propiedad, presentes ya en las primeras constituciones occidentales, tiene un matiz individualista, como esfera que ha de ser protegida frente a la actuación de terceros, incluido el Estado. Esa noción se valora que debe ser superada, pues el derecho a un medio ambiente sano, no pertenece en exclusiva a la persona individual, sino que se extiende a la colectividad. Por tanto, el interés del individuo debe supeditarse al interés de la comunidad, matizando el ejercicio de cualquier derecho.

El derecho a un medio ambiente sano actúa, pues, cómo límite al ejercicio de los derechos. Dentro del ordenamiento jurídico cubano, de acuerdo al Código Civil vigente en Cuba, todo derecho, incluido el de propiedad, debe ejercerse de acuerdo a su contenido social y finalidad, conforme a su destino socioeconómico (artículo 129), de modo racional (artículo 132), y dentro de los límites generalmente admitidos (artículo170.2). De modo más preciso, refiriéndose específicamente a la protección del ambiente como límite al derecho de propiedad, el Código Civil reconoce de forma explícita a lo dispuesto en la legislación ambiental, pues en el artículo 131.1, faculta al propietario del terreno para que haga en él obras, plantaciones y excavaciones, con las "limitaciones" establecidas en las disposiciones legales, haciendo especial referencia a las relativas a la "...protección del patrimonio nacional y cultural, y a los recursos naturales y el medio ambiente”. En segundo 
apartado del propio precepto obliga al titular del predio a adoptar las mayores precauciones a fin evitar todo “...peligro, daño, contaminación o perjuicio a las personas o a los bienes”. CÁNOVAS (2012).

Con ello, se valora que alcanzar el principio del desarrollo sostenible es considerado en la actualidad como el paradigma más acuciante dentro del Derecho Ambiental, la lectura de la doctrina Hispanoamericana viene señalando que el desarrollo sostenible se encuentra en la base de la categoría de "instrumentos de mercado de carácter cooperador", que compatibilice la tutela ambiental con el crecimiento de la economía, de aquí la articulación del Derecho Administrativo Ambiental. Esto ha permitido que se vaya consolidando como principio general del Derecho Administrativo Ambiental, a partir de la actualización de las técnicas jurídicas de tutela ambiental con la gestión compartida en el medio ambiente, al decir de MARTIN (1991).

Siguiendo a MARTín (1991), quien, en sus estudios desde la academia en España, refiere que el Derecho Ambiental, sobre el mega principio -desarrollo sostenible- considera: el sector privado (incluidas las grandes empresas y las pequeñas) tiene el deber de contribuir a la evolución de comunidades y sociedades equitativas y sostenibles (Principio 24), y que las empresas del sector privado deben cumplir la obligación de rendir cuentas, en un entorno reglamentario, transparente y estable (Principio 26).

Por ello, se razona que la formación ambiental, es uno de los principales desafíos del quehacer de las Universidades, en este caso le corresponde este mandato al Ministerio de Educación Superior, orientado hacia la necesidad de formar profesionales capaces de operar cambios en el comportamiento de la sociedad en su conjunto, así como de la transformación del conocimiento y la innovación de tecnologías para la solución de los problemas ambientales, e introducir el nuevo saber ambiental, el desarrollo sostenible. Ya se señalaba que el derecho a un medio ambiente sano no está formulado de forma expresa en el texto constitucional, pero el mismo se hace explícito en la Ley de Medio Ambiente, Ley $\mathrm{N}^{\mathrm{o}} .81$ de 1997, que lo recoge como uno de los principios que la inspiran, a partir del cual deben ser interpretados sus preceptos (artículo 4, inciso a) de este cuerpo jurídico. 
La Ley No. 81 de 1997, actualiza principios, objetivos y conceptos básicos de la política ambiental en Cuba, el marco institucional y los instrumentos para su materialización, las atribuciones, funciones y deberes de los órganos y organismos estatales y en general, los derechos y obligaciones de las personas naturales y jurídicas. La misma cubre un amplio espectro que incluye 163 artículos. Regula los "principios que rigen la política ambiental y las normas básicas para regular la gestión ambiental del Estado y las acciones de los individuos y la sociedad en general, a fin de proteger el medio ambiente y contribuir a alcanzar los objetivos del desarrollo sostenible del país". (Rubio Legra, 1999); (Soler, 2013); (Rey \& Cruz 2017)

Adentrarnos en la conceptualización de la formación, según el Diccionario Larousse Ilustrado, es la acción de formar o formarse. Es sinónimo de educación e instrucción. DE LA LUZ Y CABAllero (1952) en la materia educativa considera que, "formar es dar carrera para vivir". "Es el proceso y el resultado cuya función es la de preparar al hombre en todos los aspectos de su personalidad" (Álvarez, C. 1999). A los fines de la Educación Superior cubana, el concepto formación se emplea para caracterizar el proceso sustantivo desarrollado en las universidades con el objetivo de preparar integralmente al estudiante en una determinada carrera universitaria y abarca, tanto los estudios de pregrado como los de postgrado (HORRUITINIER, 2007).

Por consiguiente, en la visión del contexto nacional, influyen las cuestiones medulares como el crecimiento económico, la población y el territorio, la mejoría de sus condiciones en cuanto al medio ambiente y la calidad de vida de sus habitantes; obliga a los gobiernos a lograr un equilibrio territorial, funcional y económico, en el ámbito de todo el sistema, ejemplo de ello ha sido con el perfeccionamiento jurídico que se acomete en Cuba a raíz de los Lineamientos aprobados en el año 2017, en la Asamblea Nacional del Poder Popular. Que como muestra de lo señalado, han sido la serie de cuerpos jurídicos que han incidido en el perfeccionamiento jurídico en materia tributaria con el impuesto ambiental, en la de aguas para el control del recurso hídrico, en la inversión extranjera para la protección del entorno natural, en lo laboral para la protección del trabajador agrícola, entre 
otros. Aquí se demuestra la transversalidad de la protección del medio ambiente, donde concurren saberes y diversas disciplinas en su prevención, formación, incidente en la cultura para una adecuada conciencia ambiental.

En este contexto, el Plan de Estado para el enfrentamiento al cambio climático en Cuba (Tarea Vida), como acto administrativo tiene como antecedentes las investigaciones que acerca del cambio climático se inician en la Academia de Ciencias de Cuba en el año 1991, desde el siglo pasado, y que se intensificaron a partir de noviembre del 2004, luego de un exhaustivo análisis y debate sobre los impactos negativos causados por los huracanes Charley e Iván en el occidente del país. Datos que son avalados por estudios científicos que ratifican que hoy el clima de la Isla de Cuba es cada vez más cálido y extremo. La temperatura media anual aumentó en 0,9 grados centígrados desde mediados del siglo pasado. Se ha observado gran variabilidad en la actividad ciclónica, toda vez que desde el 2001, hasta la fecha hemos sido afectados por nueve huracanes intensos, hecho sin precedentes en la historia de Cuba en materia de meteorología. (CITMA, 2017).

La Tarea Vida, como se le conoce, es aprobada por el Consejo de Ministros el 25 de abril de 2017, está inspirada en el pensamiento de FIDEL CASTRO, cuando en la Cumbre de La Tierra en Río de Janeiro, el 12 de junio de 1992, expresó: “...Una importante especie biológica está en riesgo de desaparecer por la rápida y progresiva liquidación de sus condiciones naturales de vida: el hombre...". Tiene un alcance y jerarquía superiores, los actualiza e incluye la dimensión territorial. Asimismo, requiere concebir y ejecutar un programa de inversiones progresivas, a corto (2020), mediano (2030), largo (2050) y muy largo plazos (2100).

Ello permite señalar que la conceptualización de la educación ambiental y educación jurídica ambiental se han ido perfeccionando y complejizando a medida en que se hace más evidente un futuro donde es posible la extinción de la humanidad, y se ha llegado a un plano transdisciplinar y multidisciplinar para contribuir a garantizar el desarrollo sostenible como nuevo saber ambiental. Donde la universidad cubana tiene un papel protagónico en este sentido para su consecución. Por 
ello, la formación de los estudiantes en la educación superior persigue la tarea de constituir desde las mismas aulas los profesionales competentes y calificados que requiere la sociedad para impulsar el desarrollo económico, político, social y cultural de la nación. Se aspira a que los egresados sean capaces de enfrentar en condiciones óptimas los retos y dificultades que la vida laboral impone y que dicho desenlace sea favorable con competencias.

En tal sentido, los enfoques que sobre la educación superior se han propuestos reafirman la necesidad de ir perfeccionando los planes de estudios y adaptar los mismos a las realidades concretas y a las necesidades básicas de la práctica profesional. Ello incidirá en el desarrollo de la producción agroalimentaria que garantice el cumplimiento de principios como el de soberanía alimentaria y seguridad alimentaria para la sustitución de importaciones, es un reto declarado en la política agroindustrial de Cuba en el contexto de actualización del modelo económico y social.

La visión dirigida hacia el año 2020, el documento "Educación Superior en el Siglo XXI: Líneas estratégicas de desarrollo", señala que para el 2020, las IES deben haber: "incorporado a los programas docentes elementos formativos orientados a fortalecer la comprensión del entorno social y natural, el desarrollo sustentable, los derechos humanos, la educación para la democracia, la cultura para la paz y la tolerancia." Cerramos las ideas en este ensayo, al ponderar la postura de LEFF (2009), quien señala ... "El ambiente deja de convertirse en un objeto para tornarse en un saber"; por eso, quisiera resaltar la importancia de la formación de las Alianzas en la cuestión ambiental; estas fuerzas como modelos de unión, trabajo en equipo, y que se incluya, por ende, el área educativa, como pilar constructivista y de elemento de cambio; que así se formen los "Colectivos de educadores" ... (ONG, Universidades, Municipios, etc.)

\section{Conclusiones}

La Declaración de Johannesburgo sobre el Desarrollo Sostenible en el 2002, acepta de manera expresa "la realidad de que la sociedad mundial tiene los medios y recursos para responder a 
los retos" planteados para superar la supuesta dicotomía entre protección ambiental y desarrollo económico por vía de la armonización de ambos procesos. Luego en la cumbre Río+20, del 2012, sobre el paradigma del desarrollo sostenible, se avanzó en el logro de una economía verde en el contexto del desarrollo sostenible y la erradicación de la pobreza, y el marco institucional para el desarrollo sostenible.

Los cuerpos jurídicos en los ordenamientos jurídicos que han dispuesto la protección del medio ambiente no han resuelto mitigar los problemas ambientales en pos del desarrollo sostenible; no obstante, este se ha continuado deteriorando en el siglo XXI. Para superar este fracaso se necesita de la participación ciudadana, que defienda la aplicación del Derecho Ambiental, pero esta defensa depende del conocimiento del Derecho Ambiental, de aquí que sea necesario el fomento de la formación jurídico ambiental desde la academia en cumplimiento de las políticas públicas.

A las Universidades, les corresponderá a través de la formación jurídica ambiental asumir los retos de la problemática del deterioro del entorno, proponiendo para ello principios de acción que contribuyan de la manera más efectiva a la realización de los postulados hacia el desarrollo sostenible con respeto a la armonía del ambiente natural y de la vida en cada una de las áreas de investigación, tanto en la tecnológica, como en las de las ciencias naturales, humanas y sociales, ello sigue siendo un reto por alcanzar.

A las Facultades de Derecho les corresponderá una decisiva contribución en la difusión de este conocimiento con el uso de las Tic. No basta que enseñen Derecho Ambiental a sus estudiantes de Derecho, sino que también, desde ellas, este conocimiento tendría que irradiarse hacia las otras Facultades y hacia la sociedad en general de manera integradora por la transversalidad de la cuestión ambiental, sin educación ambiental no será posible alcanzar el un desarrollo sostenible como nuevo saber ambiental.

En la región de América Latina se ha reconocido un Derecho Ambiental Latinoamericano, este ha sido el resultado del reconocimiento del pluralismo jurídico De Jure, donde en las cartas 
políticas de Bolivia y Ecuador se reconoció a la naturaleza como sujeto, lo que lo diferencia del Derecho Ambiental europeo. Este acontecimiento ha generado un nuevo saber ambiental para ser estudiado en la formación jurídico ambiental en la academia.

\section{Referencias bibliográficas}

Antúnez Sánchez, A. (2015) Los principios del Derecho Ambiental que informan la auditoría ambiental en su aplicación por la Entidad Fiscalizadora Superior en Cuba, Revista De Jure, México.

Antúnez Sánchez, A. y Ramírez Sánchez A. (2016) La potestad inspectiva v/s auditoría pública. Ojeada histórica dentro del Derecho Administrativo Ambiental cubano, Revista Dos Tribunais Thomsonreuters, $\mathrm{N}^{\mathrm{o}} 967$, Brasil.

Antúnez Sánchez, A. \& Díaz Ocampo, E. (2018) El pluralismo jurídico en América Latina, Revista Dos Tribunais Thomsonreuters, No. 990, Brasil.

Antúnez Sánchez, A. (2018) El uso de las infotecnologías en la formación ambiental del ciudadano. Revista Derecho y Cambio Social, $N^{\mathrm{o}}$. 52, Perú.

Antúnez Sánchez, A. (2018) La hipercultura en la formación jurídica, Revista Urbe Ius, Argentina. Antúnez Sánchez, A. (2018) La formación ambiental. Una necesidad en el siglo XXI con el nuevo saber ambiental, Revista Murmullos del Sur, México.

Agenda 2030, los Objetivos de Desarrollo Sostenible (2018) Una oportunidad para América Latina y el Caribe, CEPAL.

Alli Aranguren, J. (2006) Del desarrollo sostenible a la sostenibilidad. Pensar globalmente y actual localmente, Revista de Derecho Urbanístico y Medio Ambiente, Nº 226, España, pp.139-211 Ayes Ametller, G. (2013) Medio ambiente: Impacto y desarrollo, Editorial Científico-Técnica, La Habana. 
Bellorio Clabot, D. (2013) El nuevo paradigma ambiental y jurídico, V Foro ambiental Internacional, Argentina, pp. 1-24.

Bifani, P. (1999) Medio ambiente y desarrollo sostenible, Editorial IEPALA, Guadalajara.

Brañes Ballesteros, R. (2001) Informe del Derecho Ambiental en Latinoamérica, análisis históricodoctrinal y jurídico desde el Derecho Ambiental, PNUMA, México, 9-114.

Brañes Ballesteros, R. (2001) Manual de Derecho Ambiental mexicano, Fondo Cultura, 2a edición, México.

Caferrata, N. (2013) Análisis del marco regulatorio en los países de América Latina y el Caribe. Economía verde en el contexto del desarrollo sostenible y erradicación de la pobreza, PNUMA.

Cánovas González, D. (2012) Necesidades y potencialidades del Derecho Ambiental cubano, CITMA, La Habana.

Caraballo Maqueira, L. (2007) El pensamiento ambiental cubano, Derecho Ambiental Cubano, $2^{\mathrm{a}}$ edición, Editorial Félix Varela, La Habana.

Cabero, J. \& Llorente, María del Carmen. (2005) Las TIC y la Educación Ambiental, Revista Latinoamericana de Tecnología Educativa, $N^{0}$. 4, España, pp. 9-26.

Corbetta, S. (2015) Pensamiento Ambiental Latinoamericano y Educación Ambiental, Voces en el Fénix. Voces de la tierra. Revista Desarrollo y Medio Ambiente, Nº. 43, Universidad de Buenos Aires.

Di Cagno, V. (2005) La Protección del Medio Ambiente en Cuba, Editorial Ciencias Sociales, La Habana.

Delgado Díaz, C. (2006) La educación ambiental desde la perspectiva política, Cuba Verde, Editorial José Martí, La Habana.

Escasena, J. (1990) La evolución de la legalidad en Cuba, Editorial de Ciencias Sociales, La Habana. Harlem Burtland, G. (1984) Informe Nuestro Futuro Común, ONU. 
Fernández Rubio-Legrá, Á. (1999) Ley No. 81 de 1997, del Medio Ambiente. En más de 150 preguntas y respuestas, Editorial Ministerio de Justicia, La Habana.

Fernández Rubio-Legra, Á. (1999) Derecho Ambiental Internacional, Editorial AFR, La Habana.

Martín Mateo, R. (1980) El ambiente como objeto de derecho, Revista Derecho y Medio Ambiente, $\mathrm{N}^{\mathrm{o}}$. 4, España.

Martín Mateo, R. (1991) Tratado de Derecho Ambiental, 1ª edición, Editorial Trivium, España.

Mateo Rodríguez, J. (2001) La cultura de la naturaleza como base de la educación ambiental. Anuario de Ecología, Cultura y Sociedad, $\mathrm{N}^{\mathrm{o}}$. 1, La Habana.

Mateo Rodríguez, J. (2003) Pensamiento Sostenibilista y Educación Ambiental: ¿Entrecruzamiento o Articulación? IV Congreso Iberoamericano de Educación Ambiental, La Habana.

Matilla Correa, A. et al. (2017) Cinco principios jurídico-administrativos en clave teórica de buena administración: eficacia, eficiencia, objetividad, economía o economicidad y celeridad. Tendencias Actuales del Derecho Administrativo, Editorial UNIJURIS, La Habana

Molano, N. (2014) La formación ambiental en la educación superior: una revisión necesaria, Revista Luna Azul, N 39, Colombia, pp. 186-206.

Novo Villaverde, M. (1995) Educación Ambiental y desarrollo sostenible, Educación Ambiental: Cuestiones y propuestas, Obra Social de Cajamurcia, Murcia.

Novo Villaverde, M. (2006) Educación ambiental. Desarrollo sostenible y globalización, Revista de Educación Ambiental, Nº 6, México.

Novo Villaverde, M. (2009) La educación ambiental, una genuina educación para el desarrollo sostenible. Revista de Educación, Número extraordinario, España, pp.195-217.

González Novo, T. (1998) Cuba, su medio ambiente después del medio milenio, Editorial CientíficoTécnica, La Habana.

González, E. (2015) Sociología Agraria: Orígenes, evolución y problemas actuales. Sociología Agraria. Transformaciones Agrarias en Cuba y América Latina, Universidad de La Habana. 
Lavígne, M. (2007) La educación ambiental para el desarrollo sostenible, Editorial Pueblo y Educación, La Habana.

Leff Zimerman, E. (2000) Saber Ambiental, Editorial Siglo XXI, México.

Leff Zimerman, E. (2009) Pensamiento Ambiental Latinoamericano: Patrimonio de un Saber para la sustentabilidad, VI Congreso Iberoamericano de Educación Ambiental, Buenos Aires, pp. 221-222.

Leff Zimerman, E. (2006) Aventuras de la Epistemología Ambiental: de la articulación de ciencias al diálogo de saberes, Editorial siglo XXI, Colombia.

Loperena Rota, D. (2003) Desarrollo sostenible y globalización, Editorial Thomson-Aranzadi, Argentina.

Lorenzetti, R. L. (2011) El paradigma ambiental, Ministerio de la Corte Suprema, Argentina.

Sanz Rubiales, I. (2014) Cambio climático y Unión Europea: presente y futuro del mercado europeo de emisiones, Editorial Tirant Lo Blanch, España.

Soler Del Sol, A. (2013) El Derecho al alcance de todos, Ley No.81 Ley del Medio Ambiente, Editorial ONBC, La Habana

Rosa Moreno, J. (2000) El Derecho Ambiental en Latinoamérica, Integración económica y medio ambiente en América Latina, Editorial McGraw-Hill, Madrid, pp.13-21.

Rey Santos O. y Cruz Sardiñas, T. (2017) La Ley del Medio Ambiente: 20 años después, Editorial UNIJURIS, La Habana.

Jordano Fraga, J. (1995) La protección del derecho a un medio ambiente adecuado, Editorial José María Bosch, Barcelona.

Jordano Fraga, J. (2013) El futuro del Derecho Ambiental, Revista Medio Ambiente y Derecho, España.

Jaquenod de Zsogon, S. (2001) Derecho Ambiental en el nuevo milenio. Una estrategia para el Derecho Ambiental, Revista de Estudios Locales (Cunal), Nº 1, España. 
Juste Ruiz, J. (1999) Derecho Internacional del Medio Ambiente, Editorial MacGraw Hill, Madrid.

Jiménez, R., y Antón, N. (2014) Agroecología y seguridad alimentaria. Una visión desde Cuba. Estudios del Desarrollo Social: Cuba y América Latina.

Parejo Alfonso, L. (2013) El derecho al medio ambiente y la actuación de la Administración Pública, Editorial Aranzadi, España.

Peña Chacón, M. (2016) Derecho Ambiental efectivo, $1^{a}$ edición, Serie Derecho Ambiental, Costa Rica.

Valdés Valdés, O. (2002) La educación ambiental y la protección del medio ambiente, Revista Educación, Nº 105, La Habana.

Valdés, J. (2015) La revolución agraria cubana: logros y desafíos. Sociología Agraria. Transformaciones Agrarias en Cuba y América Latina, Universidad de La Habana.

Velázquez de Castro, F. (2002) La educación ambiental en el siglo XXI, Grupo Editorial Universitario, Granada.

Villavella Armengol, C. (2012) El Derecho constitucional del siglo XXI en Latinoamérica: un cambio de paradigma. Estudios sobre el nuevo constitucionalismo Latinoamericano, Editorial Tirant lo Blanch, Valencia, pp.51-76.

Zaffaroni, E. (2011) La Pachamama y el humano, $1^{\text {a }}$ edición, Editorial Madres de la Plaza de Mayo, Buenos Aires. 